OPEN ACCESS

Edited by:

Beiyan Nan,

Texas A\&M University, USA

Reviewed by:

Paul S. Hoffman,

University of Virginia, USA

Héctor Toledo,

Universidad de Chile, Chile

*Correspondence:

Alberto Danielli,

Department of Pharmacy and

Biotechnology (FaBiT), University of Bologna, Via Selmi 3, 40126 Bologna,

Italy

alberto.danielli@unibo.it

Specialty section: This article was submitted to

Food Microbiology,

a section of the journal

Frontiers in Microbiology

Received: 29 May 2015

Accepted: 31 July 2015

Published: 19 August 2015

Citation:

Pelliciari S, Vannini A, Roncarati D and Danielli A (2015) The allosteric behavior of Fur mediates oxidative stress signal transduction

in Helicobacter pylori.

Front. Microbiol. 6:840.

doi: 10.3389/fmich.2015.00840

\section{The allosteric behavior of Fur mediates oxidative stress signal transduction in Helicobacter pylori}

\author{
Simone Pelliciari, Andrea Vannini, Davide Roncarati and Alberto Danielli* \\ Department of Pharmacy and Biotechnology (FaBiT), University of Bologna, Bologna, Italy
}

The microaerophilic gastric pathogen Helicobacter pylori is exposed to oxidative stress originating from the aerobic environment, the oxidative burst of phagocytes and the formation of reactive oxygen species, catalyzed by iron excess. Accordingly, the expression of genes involved in oxidative stress defense have been repeatedly linked to the ferric uptake regulator Fur. Moreover, mutations in the Fur protein affect the resistance to metronidazole, likely due to loss-of-function in the regulation of genes involved in redox control. Although many advances in the molecular understanding of HpFur function were made, little is known about the mechanisms that enable Fur to mediate the responses to oxidative stress. Here we show that iron-inducible, apo-Fur repressed genes, such as pfr and hydA, are induced shortly after oxidative stress, while their oxidative induction is lost in a fur knockout strain. On the contrary, holo-Fur repressed genes, such as frpB1 and fecA1, vary modestly in response to oxidative stress. This indicates that the oxidative stress signal specifically targets apo-Fur repressed genes, rather than impairing indiscriminately the regulatory function of Fur. Footprinting analyses showed that the oxidative signal strongly impairs the binding affinity of Fur toward apo-operators, while the binding toward holo-operators is less affected. Further evidence is presented that a reduced state of Fur is needed to maintain apo-repression, while oxidative conditions shift the preferred binding architecture of Fur toward the holo-operator binding conformation, even in the absence of iron. Together the results demonstrate that the allosteric regulation of Fur enables transduction of oxidative stress signals in $\mathrm{H}$. pylori, supporting the concept that apo-Fur repressed genes can be considered oxidation inducible Fur regulatory targets. These findings may have important implications in the study of $H$. pylori treatment and resistance to antibiotics.

Keywords: ferric uptake regulator, oxidative stress, antibiotic resistance, allosteric regulation, redox regulation, metalloproteins, metal homeostasis, transcriptional regulation

\section{Introduction}

Helicobacter pylori is an obligate microaerophilic human pathobiont that colonizes the gastric mucosa of half of the world's population. Infections can persist asymptomatically for the lifespan of the host. However, in many cases the colonization of $H$. pylori constitutes a major cause of acute and chronic gastritis, gastric and duodenal ulcer diseases, as well as gastric cancer (Salama et al., 2013). The microaerophilic nature renders the bacterium highly vulnerable to oxygen toxicity originating from the aerobic environment and endogenous sources of reactive oxygen species (ROS; Hazell et al., 2001). In addition, $H$. pylori has to counter exogenous sources of ROS derived by the inflammatory 
response of the gastric epithelium (Bagchi et al., 1996), eventually leading to the oxidative burst of infiltrating macrophages and neutrophils (Ramarao et al., 2000). As such, the bacterium has adapted to neutralize noxious oxigen species by expressing a rich repertoire of antioxidant factors and enzymes (Wang et al., 2006). Even though many advances have been made in understanding their molecular function and regulation, it is less clear how the oxidative signal is transduced by the bacterium to provide the coordinated responses to counteract the oxidative damage. In fact, the $H$. pylori genome lacks annotated orthologs of potential oxidative stress regulators involved in the transcriptional control of antioxidant proteins, such as OxyR, PerR, OhrR, or SoxRS (Dubbs and Mongkolsuk, 2012). Beside the post-transcriptional regulator CsrA (Barnard et al., 2004), the DNA binding (HP0119) and repair (MutS) proteins (Wang et al., 2005; Wang and Maier, 2015), and the essential orphan response regulator HsrA (HP1043), for which a role in the oxidative stress response to low levels of metronidazole (MTZ) or oxygen was recently proposed (Olekhnovich et al., 2014), the regulation of oxidative stress defenses in $H$. pylori has been repeatedly linked to the ferric uptake regulator Fur (Cooksley et al., 2003; van Vliet et al., 2004; Ernst et al., 2005; Danielli and Scarlato, 2010). Point mutations in the apo-repressed $\operatorname{sodB}$ superoxide dismutase promoter affect its Fur-dependent regulation (Carpenter et al., 2009a), while several amino acid substitutions in the coding sequence of HpFur were shown to affect resistance to MTZ (Albert et al., 2005; Choi et al., 2011), likely through the derepression of SodB (Tsugawa et al., 2011). This involvement of Fur in redox homeostasis is not surprising since the formation of hydroxyl radical species, the most reactive ROS, is intimately linked to the availability of free intracellular iron ions through the Fenton reaction (Touati, 2000). Moreover, the Fur superfamily of regulators comprises PerR and other orthologs whose roles in the transduction of oxidative stress signals have been well characterized also in other bacteria (Lee and Helmann, 2006a,b, 2007; Belzer et al., 2011; Dubbs and Mongkolsuk, 2012; Troxell and Hassan, 2013).

The Fur protein of $H$. pylori is peculiar, because of its allosteric regulation mechanism which confers the function of a transcriptional commutator switch: holo-Fur and apo-Fur each bind different regulatory elements, repressing oppositely either iron-repressible $(\mathrm{FeOFF})$ or iron-inducible $(\mathrm{FeON})$ gene targets, according to the intracellular iron concentration. Thereby, transcription of iron uptake genes such as $f r p B$ or $f e c A$ is repressed by holo-Fur when iron is abundant (Delany et al., 2001a; Danielli et al., 2009), while the transcription of genes encoding iron storage protein like the Pfr ferritin is induced (Delany et al., 2001b), along with genes coding for iron-cofactor proteins such as SodB and HydA (Ernst et al., 2005). On the contrary, when iron is limiting, the transcription of iron uptake genes is derepressed, together with the apo-Fur mediated repression of iron storage genes $(p f r)$ and genes encoding the iron-cofactored enzymes, including $\operatorname{sodB}$ and hydA (Carpenter et al., 2013). Recently it has been demonstrated that this mechanism is based on the allosteric behavior of Fur which adopts different conformations and binding architectures to DNA when complexed to the iron co-factor (Agriesti et al., 2014). The peculiar apo-repression mechanism appears to rely on the presence of an additional $\alpha$-helix at the $\mathrm{N}$-terminus of the
Fur protein, conserved in the $\varepsilon$-proteobacteria clade including H. pylori and C. jejuni (Carpenter et al., 2009b, 2013; Butcher et al., 2012; Agriesti et al., 2014). Interestingly, the point mutations in the same $\alpha$-helix have been shown to strongly influence the resistance to MTZ (Choi et al., 2011), suggesting a direct link between apo-Fur repression and oxidative stress response in $H$. pylori.

It is with this background, and with the bystanding interest in the molecular basis of $H$. pylori persistence and antibiotic resistance, that we sought to further investigate the contribution of apo- and holo-Fur to the redox homeostasis of the bacterium, trying to characterize the mechanisms that enable Fur to mediate the responses to oxidative stress.

\section{Materials and Methods}

\section{Bacterial Strains and Culture Conditions}

Helicobacter pylori strains (listed in Table 1), were revitalized from glycerol stocks on Brucella broth agar plates added with $5 \%$ fetal calf serum and Skirrow's antibiotic supplement under microaerophilic conditions in jars (Oxoid gas packs). After restreaking on fresh plates, bacteria were cultured in a $9 \% \mathrm{CO}_{2}$, $91 \%$ air atmosphere at $37^{\circ} \mathrm{C}$ and $95 \%$ humidity in a water-jacketed incubator (Thermo Forma Scientific). Liquid cultures were grown in modified Brucella broth medium supplemented with 5\% fetal bovine serum in glass flasks or $25 \mathrm{~cm}^{3}$ sterile plastic flasks with vented cap (Corning). For transcriptional analysis, H. pylori planktonic cultures $\left(\mathrm{OD}_{600} \sim 0.8\right)$ were treated for $10 \mathrm{~min}$ either with $1 \mathrm{mM}\left(\mathrm{NH}_{4}\right)_{2} \mathrm{Fe}\left(\mathrm{SO}_{4}\right)_{2}, 150 \mu \mathrm{M}$ 2,2 Dipyridyl (Dipy) or $10 \mathrm{mM} \mathrm{H}_{2} \mathrm{O}_{2}$ before RNA extraction.

\section{DNA manipulations}

DNA manipulations were performed with standard techniques. Restriction and modification enzymes were purchased from New England Biolabs. Preparations of plasmid DNA were carried out with a NucleoBond Xtra Midi plasmid purification kit (MachereyNagel).

\section{DNAse I Footprinting}

Promoter probes were prepared as previously described (Agriesti et al., 2014). Briefly, pGEM K-F and pGEMpfr plasmids were digested with HindIII or BamHI (NEB) respectively, dephosphorylated by treatment with calf intestine phosphatase (NEB) and subsequently $5^{\prime}$-end labeled with $\left[\gamma^{-}{ }^{32} \mathrm{P}\right]$-ATP and T4 polynucleotide kinase (NEB). After a second digestion at the $3^{\prime}$-end of the probe, the DNA fragments were recovered by gel extraction. Recombinant $\mathrm{His}_{6}$-Fur was overexpressed and purified under native conditions (Delany et al., 2001b), treated with thrombin protease $(10 \mathrm{U} / \mathrm{mg})$ to remove the $\mathrm{N}$-terminal histidine tag and dialyzed against Fur Footprinting buffer $(10 \mathrm{mM}$ Tris-Cl, pH 7.85, $50 \mathrm{mM} \mathrm{NaCl}, 10 \mathrm{mM} \mathrm{KCl}, 0.02 \%$ Igepal CA-630, $10 \%$ glycerol, $0.1 \mathrm{mM} \mathrm{DTT}$ ).

The DNase I footprinting reactions were performed in $1 \mathrm{X}$ Fur footprinting buffer incubating approximatively $15 \mathrm{fmol}$ of radiolabeled probe with different amounts of Fur protein for $20 \mathrm{~min}$ at room temperature, with $300 \mathrm{ng}$ of sonicated salmon 
TABLE 1 | Bacterial strains, plasmids, and oligonucleotides.

\begin{tabular}{|c|c|c|}
\hline Helicobacter pylori strain & Genotype & References \\
\hline G27 & Clinical isolate, wild type & Xiang et al. (1995) \\
\hline G27(fur::km) & $\begin{array}{l}\text { Derived from G27 strain; bp } 25 \text { to } 434 \text { of the CDS of fur (G27_401) were substituted with a kanamycin } \\
\text { resistance cassette, } \mathrm{Km}^{\mathrm{R}}\end{array}$ & Delany et al. (2005) \\
\hline Plasmid & Description & \\
\hline pGEMK-F & $\begin{array}{l}\text { Derivative of pGEM3Z containing a } 447 \mathrm{bp} \text { EcoRI-Pstl fragment comprising the intergenic region } \\
\text { between kat } A \text { and } \operatorname{frpB} \text { and the } 5^{\prime} \text { end of each gene. Amp }{ }^{r}\end{array}$ & Delany et al. (2001b) \\
\hline pGEMpfr & $\begin{array}{l}\text { Derivative of pGemT containing the pfr-G27_615 intergenic region as a } 390 \text { bp from base } 699220 \text { to } \\
\text { base } 699609 \text { of the G27 genome, Amp }{ }^{r}\end{array}$ & Delany et al. (2001b) \\
\hline Oligos & Sequence & \\
\hline FrpB RT FW & TGTGAGAGGCATTGAAGACAGGCT & Agriesti et al. (2014) \\
\hline FrpB RT RV & CGCCTITGGTAACTTCCACGCTाT & Agriesti et al. (2014) \\
\hline Pfr RT FW & TGCTGTTCAGCCACATACCATTGC & Agriesti et al. (2014) \\
\hline Pfr RT RV & GCGCCTGAGCATAAGTITGAAGGT & Agriesti et al. (2014) \\
\hline FecA1 RT FW & AGCGTGCATGGTGTCAAAAC & This work \\
\hline FecA1 RT RV & ААСТTССТTGСТССТССАGC & This work \\
\hline HydA RT FW & GAAAGCCGCTCAATACGCAG & This work \\
\hline HydA RT RV & TTGCGCGTTAGAGGGGTTAG & This work \\
\hline 16s RT FW & GGAGTACGGTCGCAAGATTAAA & Loh et al. (2011) \\
\hline 16s RT RV & CTAGCGGATTCTCTCAATGTCAA & Loh et al. (2011) \\
\hline
\end{tabular}

sperm DNA as non-specific competitor, $150 \mu \mathrm{M}\left(\mathrm{NH}_{4}\right)_{2} \mathrm{Fe}\left(\mathrm{SO}_{4}\right)_{2}$ or $150 \mu \mathrm{M}$ Dipy, in a final volume of $50 \mu \mathrm{l}$. To perform the assay in different redox conditions, DTT ( $1 \mathrm{mM}$ or $5 \mathrm{mM}$ ) or $\mathrm{H}_{2} \mathrm{O}_{2}$ $(5 \mathrm{mM})$ were added to the binding reaction.

DNAse I (Novagen) was diluted in 1X Fur FPB added with $10 \mathrm{mM} \mathrm{CaCl}_{2}$ and $5 \mathrm{mM} \mathrm{MgCl}_{2}$. Samples containing iron and DTT were digested with $0,03 \mathrm{U}$ of DNase for $90 \mathrm{~s}$; for all the other conditions the concentration of DNase was raised to $0,15 \mathrm{U}$.

Reactions were stopped with the addition of $140 \mu \mathrm{l}$ of STOP buffer (192 mM NaOAc pH 5.2, 32 mM EDTA, 0.14\% SDS, $64 \mu \mathrm{g} / \mu \mathrm{L}$ salmon sperm DNA), then purified and extracted. Samples were resuspended in $10 \mu \mathrm{L}$ of formamide loading buffer, denatured at $100^{\circ} \mathrm{C}$ for $3 \mathrm{~min}$, separated on $8 \mathrm{M}$ urea- $6 \%$ polyacrylamide sequencing gels and autoradiographed.

\section{RNA Extraction and cDNA Synthesis}

Total RNA was extracted with TRI-Reagent (Sigma-Aldrich) following the manufacturer's protocol. To remove contaminating genomic DNA, $5 \mu \mathrm{g}$ of total RNA were treated with $1 \mathrm{U}$ DNAseI in $1 X$ DNAse buffer ( $80 \mathrm{mM}$ Hepes $\mathrm{pH} 7.5,10 \mathrm{mM} \mathrm{NaCl}, 5 \mathrm{mM}$ $\mathrm{MgCl}_{2}, 10 \mathrm{mM} \mathrm{DTT}$ ) at $37^{\circ} \mathrm{C}$ for $30 \mathrm{~min}$ in a final volume of $50 \mu \mathrm{l}$; then the samples were phenol/chloroform extracted, ethanol precipitated and resuspended in $\mathrm{RNAse}$ free $\mathrm{mQH}_{2} \mathrm{O}$.

For cDNA synthesis, $1 \mu \mathrm{g}$ of DNA-free RNA was incubated with $50 \mathrm{ng}$ of random primers in a final volume of $10 \mu \mathrm{l}$, denatured for $5 \mathrm{~min}$ at $70^{\circ} \mathrm{C}$ and immediately chilled on ice; then $5 \mathrm{U}$ of reverse transcriptase (RT-AMV, Promega), dNTPs (final concentration $1 \mathrm{mM}$ each) and RT-AMV Buffer were added and the reaction was incubated for $1 \mathrm{~h}$ at $37^{\circ} \mathrm{C}$.

\section{Real Time PCR}

Two $\mu \mathrm{L}$ of the diluted (1:5) cDNA samples were mixed with $5 \mu \mathrm{L}$ of $2 \mathrm{X}$ iTaq Universal SYBR Green Supermix (Bio-Rad) and oligonucleotides specific for the gene of interest (Table 1) in a final volume of $10 \mu \mathrm{L}$. Real time PCR was performed using the following cycling protocol: $50^{\circ} \mathrm{C}$ for $2 \mathrm{~min}, 95^{\circ} \mathrm{C}$ for $2 \mathrm{~min}$, then 40 cycles consisting of a denaturation for $15 \mathrm{~s}$ at $95^{\circ} \mathrm{C}$ followed by $1 \mathrm{~min}$ at $60^{\circ} \mathrm{C}$ (annealing and extension step). For each real time experiment, the specificity of the reaction was checked by including a melting profile at the end of the run. Data were analyzed using the $\Delta \Delta \mathrm{Ct}$ method. The levels of expression of the genes of interest were normalized against the measured level of the RNA coding for the housekeeping 16 S rRNA gene.

\section{Results}

\section{Hydrogen Peroxide Induces Apo- Fur Repressed Genes}

In order to investigate the role of Fur on the transduction of oxidative stress signals, we analyzed the transcriptional responses of Fur-regulated genes in $H$. pylori cultures exposed to hydrogen peroxide. We selected holo-Fur repressed $(\operatorname{frp} B$ and $f e c A 1)$ and apo-Fur repressed genes ( $p f r$ and hydA) since they are oppositely regulated by Fur in virtue of an extensively described allosteric regulation mechanism responsive to iron (Delany et al., 2001b; Carpenter et al., 2013; Agriesti et al., 2014). To find the optimal conditions for the analysis, several preliminary assays were carried out (data not shown): bacterial cultures were treated with 10 to $100 \mathrm{mM} \mathrm{H}_{2} \mathrm{O}_{2}$ for 5 to $20 \mathrm{~min}$, and the mRNA levels of $p f r$ and $\operatorname{frpB}$ genes were assayed by RT-qPCR and compared to the untreated samples. The more reproducible results were obtained in the samples treated with $10 \mathrm{mM}$ of $\mathrm{H}_{2} \mathrm{O}_{2}$ for $10 \mathrm{~min}$. Higher concentrations of hydrogen peroxide led to erratic variations of mRNA levels, while prolonged treatments showed a return to nearly non-stressed levels after $20 \mathrm{~min}$, with a bell-shaped trend of the response (data not shown).

Thus, planktonic cultures of wild type and $\Delta$ fur strains were treated with $10 \mathrm{mM}$ of $\mathrm{H}_{2} \mathrm{O}_{2}$ to induce the oxidative stress, or with 


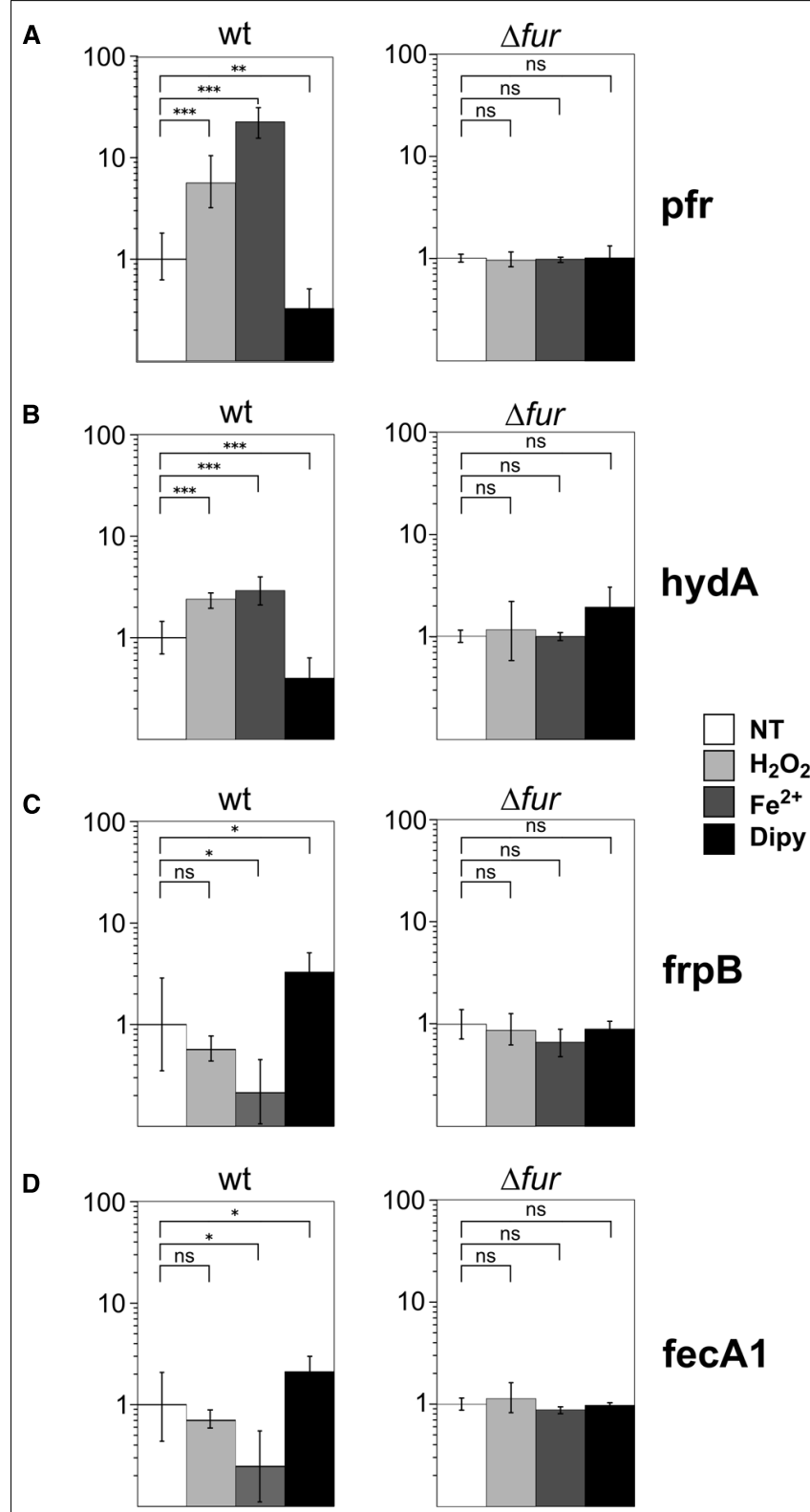

FIGURE 1 | In vivo responses to oxidative stress of holo- and apo-Fur regulated genes. Transcript levels of apo-Fur (pfr, hydA); (A,B) and holo-Fur (frpB, fecA 1); (C, D) repressed genes were assayed by RT-qPCR in wild-type and $\Delta$ fur genetic backgrounds. Results are reported as the $n$-fold variation with respect to the untreated sample (white bars); light grey, dark grey and black bars correspond to treatments with $10 \mathrm{mM} \mathrm{H}_{2} \mathrm{O}_{2}, 1 \mathrm{mM}$ iron or $150 \mu \mathrm{M}$ iron chelator, respectively, for $10 \mathrm{~min}$. Data are reported in logarithmic scale; error bars indicate the standard deviations. The significance was calculated by a Student's $t$-test. ns: non-significant; ${ }^{\star} p<0.05 ;{ }^{* \star} p<0.01 ;{ }^{\star \star \star} p<0.001$.

$1 \mathrm{mM}$ iron sulfate $\left(\mathrm{Fe}^{2+}\right)$ and $150 \mu \mathrm{M}$ iron chelator (2,2-dipyridyl; Dipy) to elicit the well-described responses occurring after iron repletion or chelation. Messenger RNA levels of genes subjected to either holo- or apo-repression were followed by RT-qPCR with results reported in Figure 1.

In the wild type strain, we observed an increase of $p f r$ transcript level in response to iron and a decrease of mRNA levels upon iron chelation, as expected for an apo-Fur regulated gene. Interestingly, a sixfold increase of $p f r$ mRNA level was also observed in response to the $\mathrm{H}_{2} \mathrm{O}_{2}$ treatment (Figure 1A). This response was lost in a $\Delta$ fur strain, suggesting that the observed regulation is Furdependent. To ascertain whether inducibility upon oxidative stress could be a conserved feature of apo-repressed Fur targets, the analysis was repeated on $h y d A$, that codes for a subunit of a quinone-reactive $\mathrm{Ni} / \mathrm{Fe}$-hydrogenase, reported previously to be apo-Fur repressed as $p f r$ (Carpenter et al., 2013). Consistently, the transcript levels of hydA were induced upon iron repletion and hydrogen peroxide treatment, and proved to be lost in a fur knockout background, paralleling the responses observed for $p f r$ (Figure 1B).

On the other hand, holo-Fur repressed genes, such as $\operatorname{fr} p B$ and $f e c A 1$, which are induced by the withdrawal of iron and repressed in a Fur- and iron-dependent fashion, exhibited a different, weak response to oxidative stress. In fact, the slight down-regulation upon hydrogen peroxide treatment resulted in both cases statistically non-significant (Figures 1C,D).

We conclude that apo-Fur but not holo-Fur repressed genes are responsive to hydrogen peroxide treatment, and that the oxidative stress signal mimics the effects of iron repletion on the transcription of these genes. Notably, the responses are lost in a $\Delta$ fur strain, suggesting that the transduction of the oxidative signal is directly or indirectly mediated by Fur.

\section{Hydrogen Peroxide Selectively Impairs Fur Binding to DNA}

To establish if the Fur protein mediates the oxidative stress signal response through a direct regulation, DNaseI footprinting assays were performed with the purified recombinant Fur protein and the radiolabeled Ppfr promoter region as probe. Binding experiments were conducted under iron repletion (Figure $2 \mathbf{A}$ ) or chelation (Figure 2B), both in reducing ( 5 mM DTT, 1 mM DTT) or oxidizing conditions $\left(5 \mathrm{mM} \mathrm{H}_{2} \mathrm{O}_{2}\right)$.

Under reducing conditions, Fur protects the Ppfr probe in correspondence of three regions when iron is chelated, pOPI, pOPII, and pOPIII, each encasing a hypersensitive band (Figure 2B; 1 mM DTT, 5 mM DTT). These regions correspond precisely, to the three previously characterized bona-fide apooperators of the P pfr promoter (Delany et al., 2001b). Under the same redox conditions, but in the presence of iron ions, Fur loses affinity for pOPI, pOPII, and pOPIII (Figure 2B; center and right panels), in agreement with the allosteric behavior reported recently for Fur on this promoter (Agriesti et al., 2014). Interestingly, a fourth, low-affinity, distal and irondependent region of protection appears (holo-pOPIV; Figure 2A), reported also originally by Delany and co-workers (Delany et al., 2001b).

When hydrogen peroxide is added to the reaction, the protection pattern conferred by Fur changes dramatically: the binding of apo-Fur to pOPII and pOPIII is strongly impaired, while a protection on the low-affinity holo-pOPIV operator appears, even in the absence of iron ions (Figure 2B, left panel). Similarly, hydrogen peroxide has a negative effect on Fur binding even in the presence of iron, with a general loss of affinity for all the apo-operators. Seemingly, also Fur binding to pOPIV is 


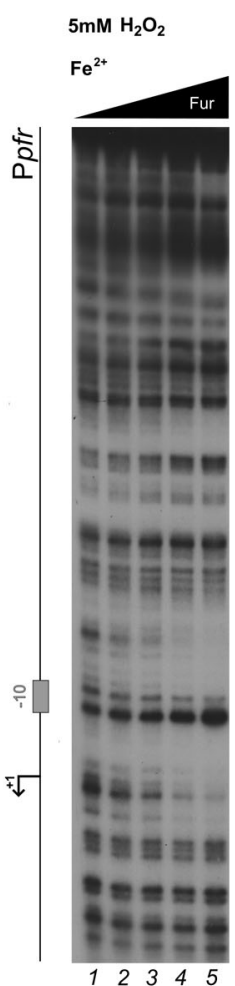

$1 \mathrm{mM}$ DTT

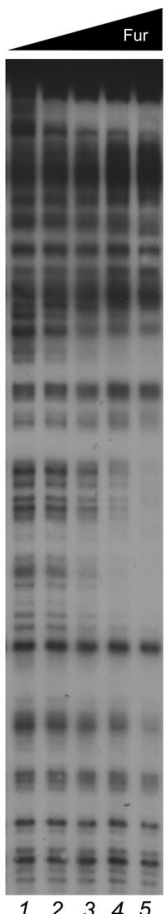

$5 \mathrm{mM}$ DTT
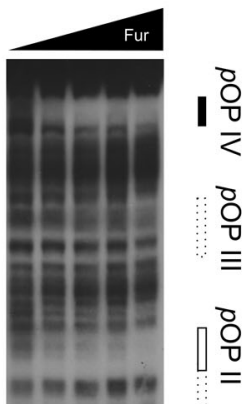

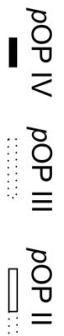

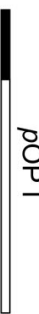

FIGURE 2 | DNase I protection patterns of Fur on the pfr promoter in reducing and oxidative conditions. DNase I footprinting assay of Fur protein on the Ppfr probe in presence of $150 \mu \mathrm{M}$ of $\left(\mathrm{NH}_{4}\right)_{2} \mathrm{Fe}\left(\mathrm{SO}_{4}\right)_{2}$ (A) or $150 \mu \mathrm{M}$ Dipyridyl (B). A schematic representation of the promoter region is reported on the left side of the panel. Regions corresponding to Fur operator elements are indicated by boxes: black, holo-Fur operators; white, apo-Fur operators.

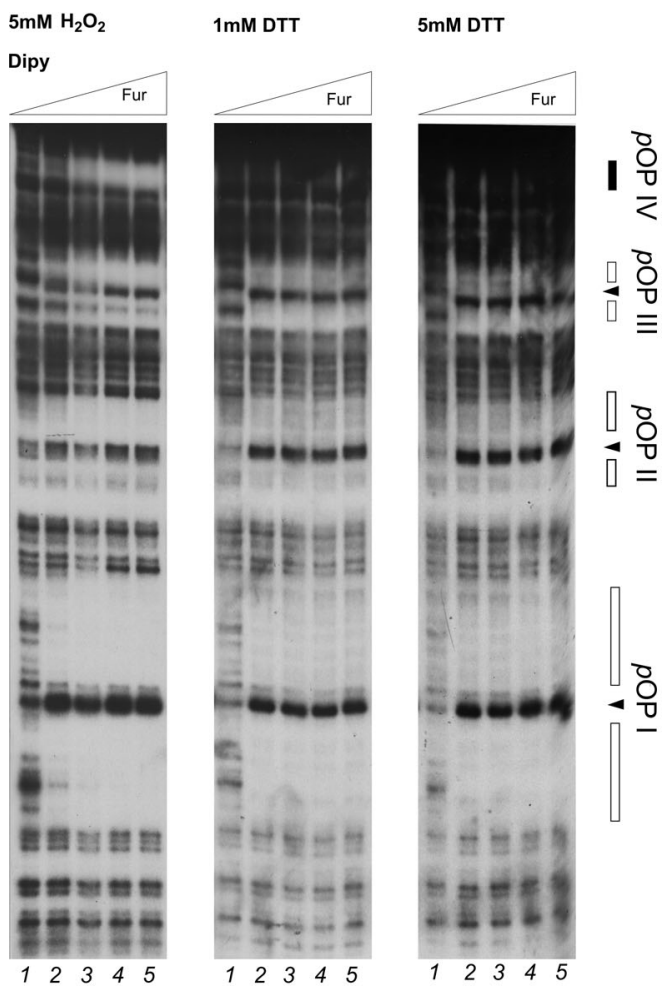

Arrowheads indicate hypersensitivity bands to DNase I treatment. Black and white triangles indicate increasing concentrations of Fur protein, in the presence of iron and iron chelator, respectively. The redox condition of the assay is indicated on the top of the footprinting experiment: $5 \mathrm{mM} \mathrm{H}_{2} \mathrm{O}_{2}$ (oxidative), $1 \mathrm{mM}$ DTT (mildly reducing), $5 \mathrm{mM}$ DTT (reducing). Lane numbers 1 to 5: 0, 29, 58, 116, and 232 nM Fur dimer. affected, resulting in the absence of a clear protected region on the Ppfr probe at the highest protein concentration (Figure 2A; left panel).

\section{Oxidative Stress Signal Transduction on Apo-repressed Fur Targets}

Since the most prominent change of Fur binding to Ppfr in response to the oxidative signal was observed especially on the distal pOPIII and pOPIV elements, additional experiments with lowered Fur protein concentration were carried out to investigate whether also the binding to the high-affinity proximal operator elements pOPI and pOPII could be affected (Figure 3). In the footprinting experiment, an equivalent Fur protection pattern in POPI and pOPII was observed at a fivefold higher protein concentration when hydrogen peroxide was added to the binding reaction, confirming the loss of apo-Fur binding also to the proximal high-affinity pOPI operator overlapping the core promoter region (Figure 3A). The same results where observed when the binding to the whole promoter region was assayed by EMSA (Figure 3B). These results demonstrate that oxidative conditions can impair the binding affinity of Fur to apooperators, and promote the binding of the protein to a low affinity holo-operator (pOPIV) even in the absence of the iron-cofactor. Recalling the robust transcriptional derepression of $p f r$ observed in vivo after hydrogen peroxide treatment, we conclude that the oxidative stress signal can be transduced in a transcriptional response on apo-repressed (FeON) Fur targets, as the direct result of a decreased binding of the Fur repressor.

\section{Oxidative Stress Imposes Different Binding Architectures of Fur}

To investigate whether a similar effect could pertain also holoFur targets, the footprinting analysis was extended to the PfrpB probe, encompassing the promoter region of the iron-repressed (FeOFF) $f r p B$ gene (Figure 4). In agreement with the allosteric behavior of Fur (Agriesti et al., 2014), iron influenced the binding affinity of the protein on this promoter oppositely with respect to Ppfr. Under reducing conditions, the highest affinity was observed in the presence of the iron co-factor for the proximal fOPI holo-operator, overlapping the core promoter, with a second region of protection (fOPII) appearing only at higher protein concentration upstream of fOPI (Figure 4A, center and right panels). When iron was chelated the affinity of Fur for these two elements swapped, resulting in the strong 


\section{A}

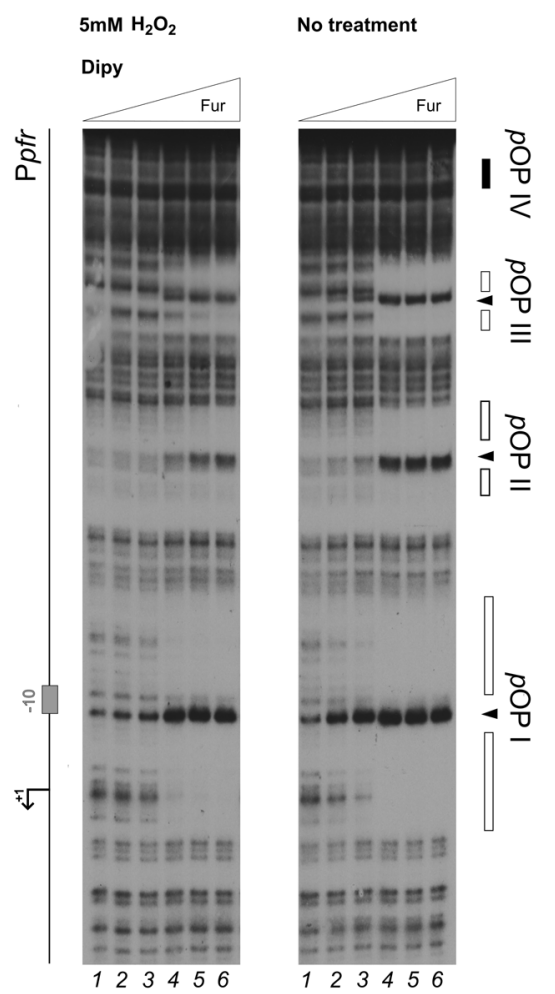

B

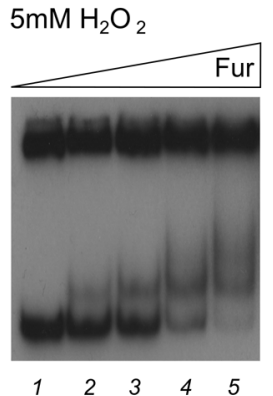

No treatment

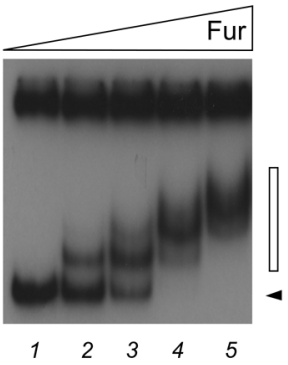

FIGURE 3 | Differential Fur binding on the apo-repressed pfr promoter in response to hydrogen peroxide. (A) Considering the extreme affinity of the protein for the Ppfr OPI element, we performed a footprinting at lower Fur concentrations. The protein was preincubated with the Ppfr probe in binding buffer containing $1 \mathrm{mM}$ DTT and $150 \mu \mathrm{M}$ Dipyridyl for $10 \mathrm{~min}$, then $5 \mathrm{mM}$ $\mathrm{H}_{2} \mathrm{O}_{2}$ was added and the binding reaction was incubated for further $10 \mathrm{~min}$ (left panel); the control reaction (right panel) was treated with the same volume of water. Legends and symbols as in Figure 2. Lanes 1-5: 0, 0.3, 0.6, 3.3, and $8 \mathrm{nM}$ Fur dimer, respectively. (B) EMSA performed on the pfr promoter probe with $1 \mathrm{mM} \mathrm{DTT}$ or $5 \mathrm{mM} \mathrm{H}_{2} \mathrm{O}_{2}$, in the presence of $150 \mu \mathrm{M}$ Dipyridyl. Lanes 1-5: 0, 0.83, 1.7, 3.4, and 6.8 nM Fur dimer. A black arrowhead indicates the free probe, the white bar denotes the ladder generated by subsequent Fur binding events on the probe.

protection of the fOPII apo-operator even at the lowest Fur concentration, while binding to the fOPI holo-operator was impaired (Figure 4B; center and right panels). In addition, a third distal apo-operator appeared, fOPIII, immediately upstream of fOPII. Note also the formation of two hypersensitive bands between the three operators, indicative of modifications affecting the DNA structure.

Strikingly, the treatment with hydrogen peroxide induced distinct modifications in the protection patterns of Fur. The high-affinity binding to the fOPII and fOPIII apo-operators was abolished (Figure 4B, left panel), while the iron-dependent binding to the fOPI holo-operator was only modestly affected (Figure 4A, left panel). In addition, hydrogen peroxide provoked a Fur-dependent protection of fOPI which resembled that of the holo-protein even though the iron co-factor was chelated (Figure 4B, left panel), paralleling the effect observed for pOPIV on the Ppfr promoter (Figure 2B; left panel). Thus, the oxidative stress signal promotes a swap in the binding architecture of Fur, impairing the binding to apo-operators and favoring to a certain extent the binding of holo-operators which require a different binding architecture of the regulator. In other words, oxidative stress induces holo-mimetic binding architectures, which appear to disfavor the binding to the apo-operators.

\section{Cumulative Effects of Fur Binding Affinity and Fur Binding Conformation to the frpB Promoter}

The allosteric behavior of Fur induced by hydrogen peroxide suggests that the oxidative stress signal specifically targets apoFur repressed genes, rather than impairing indiscriminately the regulatory function of Fur. To ascertain this hypothesis and better estimate the affinity loss on holo-operators, an additional set of footprinting analyses on the $\mathrm{P} f r p B$ promoter was conducted, with lowered Fur protein concentrations (Figure 5). Under reducing conditions, the protection of the fOPI holo-operator is partial at $4 \mathrm{nM}$ and results in a complete protection at $8 \mathrm{nM}$ Fur dimer (Figure 5; right panel, lanes 2-3). After hydrogen peroxide treatment similar protections were elicited only at $34 \mathrm{nM}$ Fur dimer (left panel, lane 5). Thus we can estimate a three- to fourfold loss of holo-Fur affinity for fOPI provoked by the oxidative stress signal. However, this effect can be compensated by the gain in apo-Fur binding affinity for the same operator (Figure 4B). This evidence explains the observed responses to oxidative stress under physiological growth conditions, in which holo-Fur repressed targets such as $f r p B$ and $f e c A 1$ are not significantly deregulated by oxidative stress (Figures 1C,D), while apo-Fur repressed targets ( $p f r$ and $h y d A$ ) are induced by the same stimulus (Figures 1A,B).

\section{Discussion}

Helicobacter pylori is highly adapted to persist in the human gastric niche and establish lifespan infections. Several lines of evidence suggest that in this environment not only H. pylori is exposed to low pH (Scott et al., 2007), but also to oxidative stress induced by the host inflammatory response (Ramarao et al., 2000; Ding et al., 2007). To counter these conditions, which pose a threat to the integrity of proteins and genomic DNA, the bacterium adopts a rich repertoire of antioxidant detoxification factors, including DNA binding and repairing systems (Wang et al., 2005, 2006, 2012; Wang and Maier, 2015). Clearly, these systems need to be coordinately expressed in response to an oxidative stress signal. Some regulatory mechanisms were proposed in the recent past, 


\section{A}
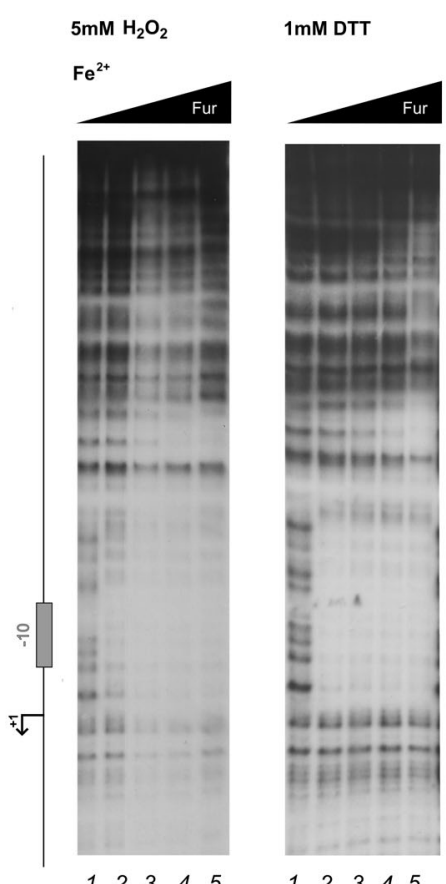

$\begin{array}{lllll}1 & 2 & 3 & 4 & 5\end{array}$
$5 \mathrm{mM}$ DTT
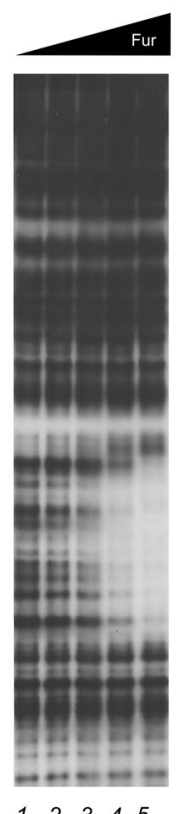

B

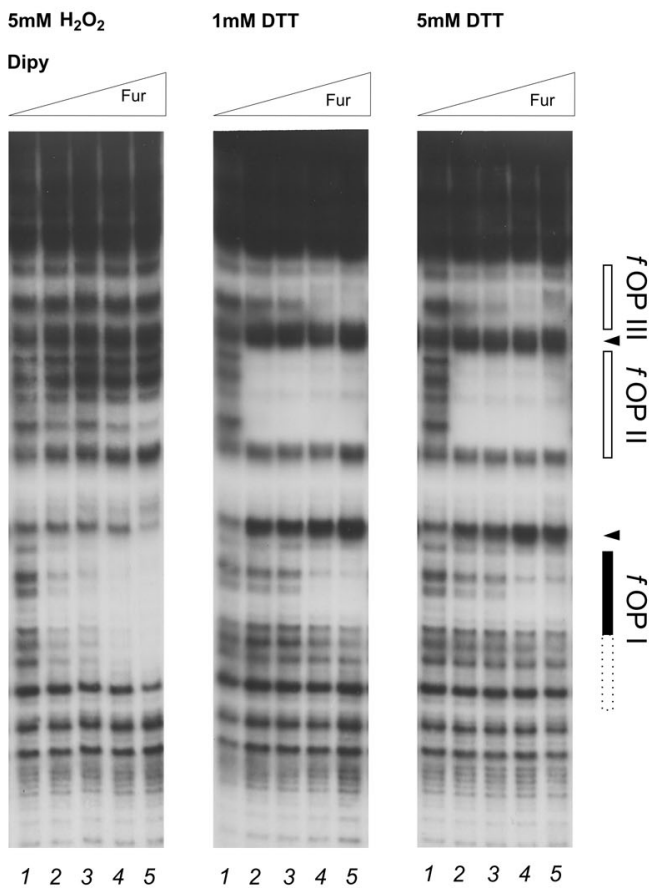

Arrowheads indicate hypersensitivity bands to DNase I digestion. Black and white triangles indicate increasing concentrations of Fur protein, in the presence of iron and iron chelator, respectively. The redox condition of the assay is indicated on the top of the footprinting experiment: $5 \mathrm{mM} \mathrm{H}_{2} \mathrm{O}_{2}$ (oxidative), $1 \mathrm{mM}$ DTT (mildly reducing), $5 \mathrm{mM}$ DTT (reducing). Lane numbers 1 to 5: 0, 29, 58, 116, and 232 nM Fur dimer.

however, our current knowledge on how the oxidative signal is transduced to provoke a transcriptional response to ROS is still limited, mainly because $H$. pylori lacks the dedicated oxygen response regulators described in other microorganisms (Danielli et al., 2010).

Here we demonstrate that HpFur can mediate the response to an oxidative signal into a specific transcriptional output. Interestingly, this transcriptional response appears to pertain mostly the apo-Fur repressed genes, i.e. genes that are inducible by free intracellular iron $(\mathrm{FeON})$. Accordingly, the treatment with hydrogen peroxide mimics in vivo the transcriptional effect exerted by Fur in response to iron repletion on these genes (Figure 1). These results are also paralleled in the DNA binding assays in vitro, in which the oxidative signal confers a holomimetic DNA binding behavior to the transcriptional regulator. In fact, while the affinity of Fur for apo-elements as well as holo-elements is impaired in response to $\mathrm{H}_{2} \mathrm{O}_{2}$, the binding architecture of the regulator is switched to a conformation favoring the binding of holo-operators even in the absence of the iron co-factor (see pOPIV and fOPI; Figures 2 and 4). The evidence that Fur adopts holo-mimetic binding conformations in response to hydrogen peroxide strongly suggests that the allosteric behavior of HpFur, responsible for its function as transcriptional commutator switch (Agriesti et al., 2014), also allows for a specific transduction of the oxidative stress signal on the apo-repressed gene targets. Therefore we propose a model supporting the hypothesis that apo-Fur repressed genes can be considered oxidation inducible Fur regulatory targets (Figure 6). Consistently, many genes that are responsive to aerobic oxygen tension (Park and Lee, 2013) or ROS have also been independently listed as Fur targets in transcriptomic and ChIPChip analyses (Ernst et al., 2005; Danielli et al., 2006; Gancz et al., 2006)

The concept that iron-inducible apo-Fur repressed genes can be considered oxidation-inducible Fur regulatory targets $(\mathrm{FeON}=\mathrm{OxON})$ is of particular interest, especially recalling the prominent role of this metallo-regulator in the transcriptional regulatory network of the bacterium (Danielli and Scarlato, 2010). This is coherent with the intimate association of redox control and iron homeostasis, and in general with the physiology of $H$. pylori. As such, apo-Fur repressed genes such as $\operatorname{sod} B$, which protect the cell from ROS excess, are induced by iron (FeON) and by oxygen stress $(\mathrm{OxON})$, likely through the same allosteric behavior of Fur described for $p f r$ and $h y d A$. Similarly, the oor operon, which codes for an essential but oxygen-labile oxidoreductase, is induced by iron through the regulatory activity of Fur (Gilbreath et al., 2012), and is likely regulated by the allosteric behavior of Fur after an oxidative stress to compensate for oxidative inactivation. Another gene that appears to be under a resembling control is the nifS gene encoding a Fe-S cluster synthesis protein (Alamuri et al., 2006). 


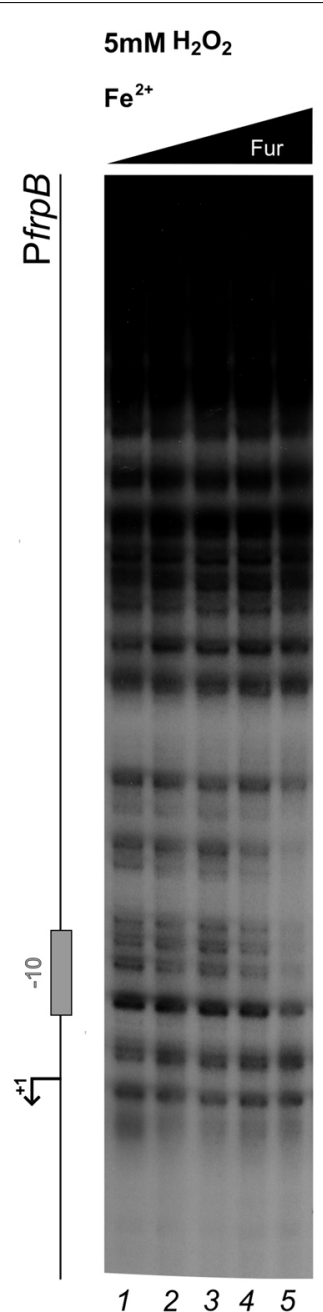

No treatment

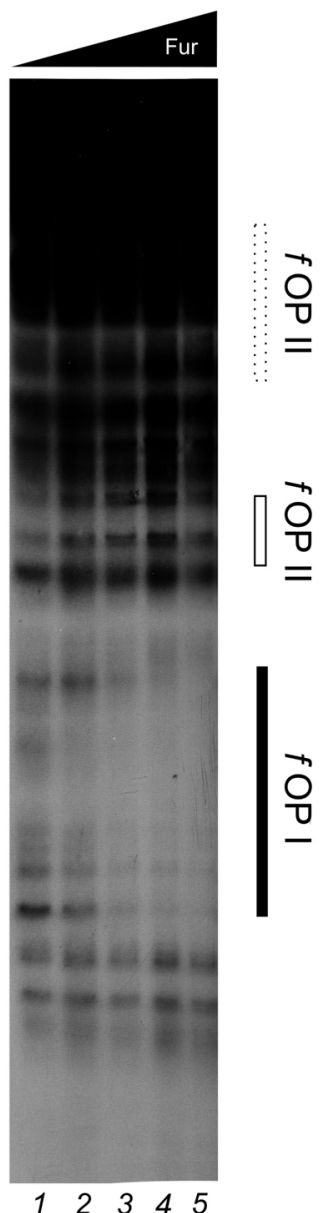

$\begin{array}{lllll}1 & 2 & 3 & 4 & 5\end{array}$

\section{Iron
uptake genes}

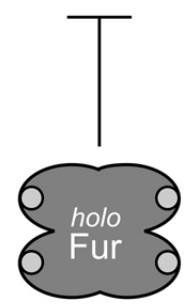

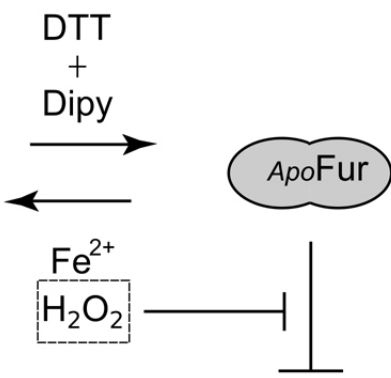

Iron
FIGURE 6 | Model of Fur behavior in response to oxidative stress. apo-Fur conformation, light gray; holo-Fur conformation, dark gray. Fur represses iron uptake genes under iron-replete and oxidative conditions. apo-Fur targets ( $p f r$ ) are only repressed under moderately reducing conditions. Upon an oxidative signal apo-Fur targets are induced, as a consequence of the allosteric behavior of Fur. Thereby, free intracellular iron can be scavenged by ferritins and metal-binding proteins, lowering the risk of iron-dependent oxidative damage that can be catalyzed by the high reactivity of this metal ion.

that activate Fur for DNA binding (Dian et al., 2011), and it is interesting to recall that point mutations affecting the formation of this site impair the repression of $\operatorname{sodB}$ by HpFur (Tsugawa et al., 2011). On the contrary, the $\mathrm{S} 3$ site is dispensable for DNA binding but its disruption reduces the HpFur DNA-binding affinity. It was suggested that S3 may amplify the DNA-binding affinity of Fur under metal repletion (Dian et al., 2011). Thus, HpFur seems to combine the features of iron-sensing (Fur) and oxidationsensing (PerR) Fur-superfamily members in one molecule. As such it will be worth exploring whether the additional regulatory metal binding site encompassed in the HpFur structure may be involved the oxidant sensing properties of Fur reported in this work.

Another important structural feature of HpFur is its unique $\mathrm{N}$-terminal extension. It has been proposed that the $\mathrm{N}$-terminal $\alpha$-helix may participate in the DNA-binding activity of apoFur, since apo-repression could not be complemented by Fur orthologs from other species that do not contain the $\mathrm{N}$-terminal extension (Miles et al., 2010). The latter is supposed to favor a Vshape conformation of HpFur in the absence of metal ion at the regulatory S2 site, as also supported by recent crystallographic studies on Campylobacter jejuni apo-Fur (Butcher et al., 2012). Strikingly, the mutations in this N-terminal extension greatly affect $H$. pylori resistance to MTZ, which needs to be activated by chemical reduction. Since MTZ antibiotic activity depends on the intracellular redox condition of the cell, the association of mutations in the N-terminal extension of Fur and MTZ resistance suggest a direct link between apo-repression and the Furdependent regulation of redox homeostasis and/or antioxidant factors in $H$. pylori. 
De facto, although many oxidative defense genes may be regulated by other transcription factors or ncRNAs, our results support for the first time the assumption that the allosteric behavior of Fur, and apo-Fur regulation in particular, is closely associated with the transduction of oxidative stress signals, with important implications in the study of $H$. pylori treatment and resistance to antibiotics.

\section{References}

Agriesti, F., Roncarati, D., Musiani, F., Del Campo, C., Iurlaro, M., Sparla, F., et al. (2014). FeON-FeOFF: the Helicobacter pylori Fur regulator commutates ironresponsive transcription by discriminative readout of opposed DNA grooves. Nucleic Acids Res. 42, 3138-3151. doi: 10.1093/nar/gkt1258

Alamuri, P., Mehta, N., Burk, A., and Maier, R. J. (2006). Regulation of the Helicobacter pylori Fe-S cluster synthesis protein NifS by iron, oxidative stress conditions, and fur. J. Bacteriol. 188, 5325-5330. doi: 10.1128/JB. 00104-06

Albert, T. J., Dailidiene, D., Dailide, G., Norton, J. E., Kalia, A., Richmond, T. A., et al. (2005). Mutation discovery in bacterial genomes: metronidazole resistance in Helicobacter pylori. Nat. Methods 2, 951-953. doi: 10.1038/nmeth805

Bagchi, D., Bhattacharya, G., and Stohs, S. J. (1996). Production of reactive oxygen species by gastric cells in association with Helicobacter pylori. Free Radic. Res. 24, 439-450. doi: 10.3109/10715769609088043

Barnard, F. M., Loughlin, M. F., Fainberg, H. P., Messenger, M. P., Ussery, D. W., Williams, P., et al. (2004). Global regulation of virulence and the stress response by CsrA in the highly adapted human gastric pathogen Helicobacter pylori. Mol. Microbiol. 51, 15-32. doi: 10.1046/j.1365-2958.2003.03788.x

Belzer, C., van Schendel, B. A., Hoogenboezem, T., Kusters, J. G., Hermans, P. W. M., van Vliet, A. H. M., et al. (2011). PerR controls peroxide- and iron-responsive expression of oxidative stress defense genes in Helicobacter hepaticus. Eur. J. Microbiol. Immunol. 1, 215-222. doi: 10.1556/EuJMI.1.2011.3.5

Butcher, J., Sarvan, S., Brunzelle, J. S., Couture, J.-F., and Stintzi, A. (2012). Structure and regulon of Campylobacter jejuni ferric uptake regulator Fur define apo-Fur regulation. Proc. Natl. Acad. Sci. U.S.A. 109, 10047-10052. doi: 10.1073/pnas.1118321109

Carpenter, B. M., Gancz, H., Gonzalez-Nieves, R. P., West, A. L., Whitmire, J. M., Michel, S. L., et al. (2009a). A single nucleotide change affects Fur-dependent regulation of sodB in H. pylori. PLoS ONE 4:e5369. doi: 10.1371/journal.pone.0005369

Carpenter, B. M., Whitmire, J. M., and Merrell, D. S. (2009b). This is not your mother's repressor: the complex role of Fur in pathogenesis. Infect. Immun. 77, 2590-2601. doi: 10.1128/IAI.00116-09

Carpenter, B. M., Gilbreath, J. J., Pich, O. Q., McKelvey, A. M., Maynard, E. L., Li, Z.-Z., et al. (2013). Identification and characterization of novel Helicobacter pylori apo-Fur-regulated target genes. J. Bacteriol. 195, 5526-5539. doi: 10.1128/JB.01026-13

Choi, S. S., Chivers, P. T., and Berg, D. E. (2011). Point mutations in Helicobacter pylori's fur regulatory gene that alter resistance to metronidazole, a prodrug activated by chemical reduction. PLOS ONE 6:e18236. doi: 10.1371/journal.pone.0018236

Cooksley, C., Jenks, P. J., Green, A., Cockayne, A., Logan, R. P. H., and Hardie, K. R. (2003). NapA protects Helicobacter pylori from oxidative stress damage, and its production is influenced by the ferric uptake regulator. J. Med. Microbiol. 52, 461-469. doi: 10.1099/jmm.0.05070-0

Danielli, A., Amore, G., and Scarlato, V. (2010). Built shallow to maintain homeostasis and persistent infection: insight into the transcriptional regulatory network of the gastric human pathogen Helicobacter pylori. PLoS Pathog. 6:e1000938. doi: 10.1371/journal.ppat.1000938

Danielli, A., Romagnoli, S., Roncarati, D., Costantino, L., Delany, I., and Scarlato, V. (2009). Growth phase and metal-dependent transcriptional regulation of the fecA genes in Helicobacter pylori. J. Bacteriol. 191, 3717-3725. doi: 10.1128/JB.01741-08

Danielli, A., Roncarati, D., Delany, I., Chiarini, V., Rappuoli, R., and Scarlato, V. (2006). In vivo dissection of the Helicobacter pylori Fur regulatory circuit by genome-wide location analysis. J. Bacteriol. 188, 4654-4662. doi: 10.1128/JB.00120-06

\section{Acknowledgments}

The authors wish to thank Vincenzo Scarlato for fruitful discussions and advice. This work was supported by a grant from the Italian Ministry of Education and University (2010P3S8BR_003) and by the University of Bologna.

Danielli, A., and Scarlato, V. (2010). Regulatory circuits in Helicobacter pylori: network motifs and regulators involved in metal-dependent responses. FEMS Microbiol. Rev. 34, 738-752. doi: 10.1111/j.1574-6976.2010.00233.x

Delany, I., Ieva, R., Soragni, A., Hilleringmann, M., Rappuoli, R., and Scarlato, V. (2005). In vitro analysis of protein-operator interactions of the NikR and fur metal-responsive regulators of coregulated genes in Helicobacter pylori. J. Bacteriol. 187, 7703-7715. doi: 10.1128/JB.187.22.7703-7715.2005

Delany, I., Pacheco, A. B., Spohn, G., Rappuoli, R., and Scarlato, V. (2001a). Iron-dependent transcription of the frpB gene of Helicobacter pylori is controlled by the Fur repressor protein. J. Bacteriol. 183, 4932-4937. doi: 10.1128/JB.183.16.4932-4937.2001

Delany, I., Spohn, G., Rappuoli, R., and Scarlato, V. (2001b). The Fur repressor controls transcription of iron-activated and -repressed genes in Helicobacter pylori. Mol. Microbiol. 42, 1297-1309. doi: 10.1046/j.1365-2958.2001. 02696.x

Dian, C., Vitale, S., Leonard, G. A., Bahlawane, C., Fauquant, C., Leduc, D., et al. (2011). The structure of the Helicobacter pylori ferric uptake regulator Fur reveals three functional metal binding sites. Mol. Microbiol. 79, 1260-1275. doi: 10.1111/j.1365-2958.2010.07517.x

Ding, S.-Z., Minohara, Y., Fan, X. J., Wang, J., Reyes, V. E., Patel, J., et al. (2007). Helicobacter pylori infection induces oxidative stress and programmed cell death in human gastric epithelial cells. Infect. Immun. 75, 4030-4039. doi: 10.1128/IAI.00172-07

Dubbs, J. M., and Mongkolsuk, S. (2012). Peroxide-sensing transcriptional regulators in bacteria. J. Bacteriol. 194, 5495-5503. doi: 10.1128/JB.00304-12

Ernst, F. D., Bereswill, S., Waidner, B., Stoof, J., Mäder, U., Kusters, J. G., et al. (2005). Transcriptional profiling of Helicobacter pylori Fur- and iron-regulated gene expression. Microbiol. Read. Engl. 151, 533-546. doi: 10.1099/mic.0.27404-0

Gancz, H., Censini, S., and Merrell, D. S. (2006). Iron and pH homeostasis intersect at the level of Fur regulation in the gastric pathogen Helicobacter pylori. Infect. Immun. 74, 602-614. doi: 10.1128/IAI.74.1.602-614.2006

Gilbreath, J. J., West, A. L., Pich, O. Q., Carpenter, B. M., Michel, S., and Merrell, D. S. (2012). Fur activates expression of the 2-oxoglutarate oxidoreductase genes (oorDABC) in Helicobacter pylori. J. Bacteriol. 194, 6490-6497. doi: 10.1128/JB.01226-12

Hazell, S. L., Harris, A. G., and Trend, M. A. (2001). "Evasion of the toxic effects of oxygen," in Helicobacter pylori: Physiology and Genetics, eds H. L. Mobley, G. L. Mendz, and S. L. Hazell (Washington, DC: ASM Press), 167-175.

Lee, J.-W., and Helmann, J. D. (2006a). Biochemical characterization of the structural $\mathrm{Zn}^{2+}$ site in the Bacillus subtilis peroxide sensor PerR. J. Biol. Chem. 281, 23567-23578. doi: 10.1074/jbc.M603968200

Lee, J.-W., and Helmann, J. D. (2006b). The PerR transcription factor senses $\mathrm{H} 2 \mathrm{O} 2$ by metal-catalysed histidine oxidation. Nature 440, 363-367. doi: 10.1038 /nature 04537

Lee, J.-W., and Helmann, J. D. (2007). Functional specialization within the Fur family of metalloregulators. Biometals Int. J. Role Met. Ions Biol. Biochem. Med. 20, 485-499. doi: 10.1007/s10534-006-9070-7

Loh, J. T., Shaffer, C. L., Piazuelo, M. B., Bravo, L. E., McClain, M. S., Correa, P., et al. (2011). Analysis of cagA in Helicobacter pylori strains from Colombian populations with contrasting gastric cancer risk reveals a biomarker for disease severity. Cancer Epidemiol. Biomarks Prev. 20, 2237-2249. doi: 10.1158/10559965.EPI-11-0548

Miles, S., Carpenter, B. M., Gancz, H., and Merrell, D. S. (2010). Helicobacter pylori apo-Fur regulation appears unconserved across species. J. Microbiol. 48, 378-386. doi: 10.1007/s12275-010-0022-0

Olekhnovich, I. N., Vitko, S., Valliere, M., and Hoffman, P. S. (2014). Response to metronidazole and oxidative stress is mediated through homeostatic regulator HsrA (HP1043) in Helicobacter pylori. J. Bacteriol. 196, 729-739. doi: 10.1128/JB.01047-13 
Park, S. A., and Lee, N. G. (2013). Global regulation of gene expression in the human gastric pathogen Helicobacter pylori in response to aerobic oxygen tension under a high carbon dioxide level. J. Microbiol. Biotechnol. 23, 451-458. doi: 10.4014/jmb.1209.09064

Ramarao, N., Gray-Owen, S. D., and Meyer, T. F. (2000). Helicobacter pylori induces but survives the extracellular release of oxygen radicals from professional phagocytes using its catalase activity. Mol. Microbiol. 38, 103-113. doi: 10.1046/j.1365-2958.2000.02114.x

Salama, N. R., Hartung, M. L., and Müller, A. (2013). Life in the human stomach: persistence strategies of the bacterial pathogen Helicobacter pylori. Nat. Rev. Microbiol. 11, 385-399. doi: 10.1038/nrmicro3016

Scott, D. R., Marcus, E. A., Wen, Y., Oh, J., and Sachs, G. (2007). Gene expression in vivo shows that Helicobacter pylori colonizes an acidic niche on the gastric surface. Proc. Natl. Acad. Sci. U.S.A. 104, 7235-7240. doi: 10.1073/pnas.0702300104

Touati, D. (2000). Iron and oxidative stress in bacteria. Arch. Biochem. Biophys. 373, 1-6. doi: 10.1006/abbi.1999.1518

Troxell, B., and Hassan, H. M. (2013). Transcriptional regulation by Ferric Uptake Regulator (Fur) in pathogenic bacteria. Front. Cell. Infect. Microbiol. 3:59. doi: 10.3389/fcimb.2013.00059

Tsugawa, H., Suzuki, H., Satoh, K., Hirata, K., Matsuzaki, J., Saito, Y., et al. (2011). Two amino acids mutation of ferric uptake regulator determines Helicobacter pylori resistance to metronidazole. Antioxid. Redox Signal. 14, 15-23. doi: 10.1089/ars.2010.3146

van Vliet, A. H., Kuipers, E. J., Stoof, J., Poppelaars, S. W., and Kusters, J. G. (2004). Acid-responsive gene induction of ammonia-producing enzymes in Helicobacter pylori is mediated via a metal-responsive repressor cascade. Infect. Immun. 72, 766-773. doi: 10.1128/IAI.72.2.766-773.2004
Wang, G., Alamuri, P., Humayun, M. Z., Taylor, D. E., and Maier, R. J. (2005). The Helicobacter pylori MutS protein confers protection from oxidative DNA damage. Mol. Microbiol. 58, 166-176. doi: 10.1111/j.1365-2958.2005.04833.x

Wang, G., Alamuri, P., and Maier, R. J. (2006). The diverse antioxidant systems of Helicobacter pylori. Mol. Microbiol. 61, 847-860. doi: 10.1111/j.13652958.2006.05302.x

Wang, G., Lo, L. F., and Maier, R. J. (2012). A histone-like protein of Helicobacter pylori protects DNA from stress damage and aids host colonization. DNA Repair. 11, 733-740. doi: 10.1016/j.dnarep.2012.06.006

Wang, G., and Maier, R. J. (2015). A novel DNA-binding protein plays an important role in Helicobacter pylori stress tolerance and survival in the host. J. Bacteriol. 197, 973-982. doi: 10.1128/JB.02489-14

Xiang, Z., Censini, S., Bayeli, P. F., Telford, J. L., Figura, N., Rappuoli, R., et al. (1995). Analysis of expression of CagA and VacA virulence factors in 43 strains of Helicobacter pylori reveals that clinical isolates can be divided into two major types and that CagA is not necessary for expression of the vacuolating cytotoxin. Infect. Immun. 63, 94-98.

Conflict of Interest Statement: The authors declare that the research was conducted in the absence of any commercial or financial relationships that could be construed as a potential conflict of interest.

Copyright (c) 2015 Pelliciari, Vannini, Roncarati and Danielli. This is an open-access article distributed under the terms of the Creative Commons Attribution License (CC $B Y$ ). The use, distribution or reproduction in other forums is permitted, provided the original author(s) or licensor are credited and that the original publication in this journal is cited, in accordance with accepted academic practice. No use, distribution or reproduction is permitted which does not comply with these terms. 